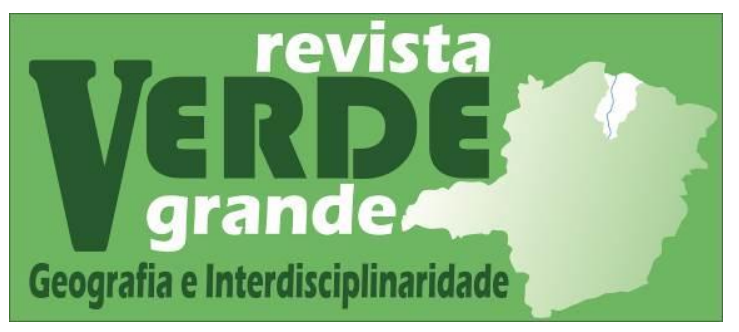

Volume 2, no. 2 (2020)

ISSN: 2675-2395

https://doi.org/10.46551/rvg26752395202025669

\title{
PENSANDO A GEOGRAFIA E SEU ENSINO A PARTIR DE PRODUÇÕES DE REALIDADE VIRTUAL
}

Thinking geography and its teaching since the productions of virtual reality

\author{
Branda Eloá Weppo ${ }^{1}$ https://orcid.org/0000-0002-2464-9862 \\ Juliano da Costa Machado Timmers² ${ }^{2}$ https://orcid.org/0000-0003-1859-4567
}

\begin{abstract}
${ }^{1}$ Mestranda em Educação pela Universidade De la Empresa - UDE, Montevidéu/Uruguai e Mestranda em Computação Aplicada pela Universidade do Vale dos Sinos -UNISINOS. E-mail: brandaweppo@live.com

${ }^{2}$ Doutor em ensino de Geografia pela Universidade Federal do Rio Grande do Sul - UFRGS - Professor de Geografia da Rede Municipal de São Leopoldo/RS. E-mail: timmersjuliano@gmail.com
\end{abstract}

\section{Resumo}

Este artigo expõe reflexões sobre idéias espaciais relacionadas à tecnologias que usamos na vida cotidiana, especialmente aquelas cujas técnicas criam os diversos modos de Realidade Virtual (RV). Metodologicamente, consideramos as discussões em torno do conceito de RV e dos dispositivos projetados para formentá-lo. Para a teoria espacial, temos uma referência importante nas considerações do geógrafo Milton Santos sobre o papel das técnicas na produção espacial contemporânea. De Gaston Bachelard, consideramos as reflexões sobre as novas idéias espaciais geradas pela microfísica e os limites do senso convencional de ciência. Com base em nossa experiência em um laboratório de tecnologia em uma universidade do sul do Brasil e no ensino fundamental escolar do mesmo país, apontamos que novas técnicas, incluindo as que apóiam a RV, devem ser analisadas pela dimensão espacial ampliada que a tornou possível. Sugerimos que técnicas possam ser usadas para colaborar coma difusãode uma visão científica mais aberta, que desenvolva o imaginário relacionado a sustentabilidade junto ao espaço em que vivemos.

Palavras-chave: Ensino; Geografia; Design; Realidade Virtual.

\begin{abstract}
This paper exposes reflections towards spatial ideas related to the technology we use in out daily life, specially the techniques which create the several modes of Virtual Reality (VR). Methodologically we consider the discussions around concepts of VR and the devices designed to provide it. To the space theory, we have an important reference in the considerations of the geographer Milton Santos over the role of techniques in the contemporary space production. From Gaston Bachelard we consider the reflections about the new space ideas generated by micro physics and the limits conventional sense of science. Based on our experience in a tech lab in a south Brazilian university and in elementary school of the same country, we point that new techniques, included the ones which support VR, should be analyzed by an open spatial dimension, the same spatial sense that allowed techniques to be created. We suggest techniques may be used in collaboration to spread a more open science view which develops an imaginary related to a more sustainable living spatiality.
\end{abstract}

Keywords: Teaching; Geography; Design; Virtual Reality. 


\section{Introdução}

O presente artigo volta-se ao desenvolvimento de reflexões sobre a dimensão espacial conjugando nossos estudos e experiência particular seja no campo do Design ou do Ensino de Geografia. Nesse contexto buscaremos ponderar o design dos diversos aparelhos que possibilitam as formas de Realidade Virtual (RV). Também analisaremos o papel das técnicas no contexto do espaço geográfico atual, as quais se conjugam como intermediárias da nossa relação espacial cotidiana.

Inicialmente destacaremos conceitos ligados aos instrumentos tecnológicos utilizados para finalidades diversas, mas que em diferentes modos criam ambientes imersivos de Realidade Virtual. Tais aparatos serão pensados a partir das experiências desenvolvidas pelo Vizlab, laboratório Multidisciplinar de Geoinformática e Visualização 3D situado dentro da Universidade do Vale Rio dos Sinos (UNISINOS), campus São Leopoldo/RS.

A seguir consideramos uma breve análise epistemológica da Geografia associada a dimensão técnica que inclui os referidos instrumentos digitais que simulam ambientes. Tal análise visa ponderar a experiência espacial junto a Realidade Virtual a partir de entendimentos sobre nossa condição espacial determinada pelos processos de Globalização. Nosso referencial teórico nessa análise é o geógrafo Milton Santos. Corroboramos com o autor para quem as técnicas têm papel destacado na produção espacial atual, pois o conjunto de aparatos tecnológicos, definidos desde celulares à óculos VR que hoje encontram-se mundialmente utilizados, nos possibilitam refletir modos de ser aí inseridas nossas identidades. A partir daí buscamos em Bachelard entendimentos que nos situem quanto aos limites e possibilidades tanto da chamada RV, assim como das noções generalizadas de espaço geográfico. Por fim ponderando nossas considerações sobre técnica e espaço, gostaríamos de compartilhar algumas ideias pedagógicas que avaliamos serem relevantes tanto para pensarmos o Ensino de Geografia escolar como para realçar os projetos dos agentes envolvidos na produção de ambientes de RV.

\section{Um olhar retrospectivo sobre as tecnologias da Realidade Virtual}

É fundamental no contexto de um artigo como esse, apresentar ideias abrangentes sobre a conceituação do que chamamos de Realidade Virtual em associação com a dinâmica evolução de artefatos que nos permitem desenvolver os ambientes virtuais. Para melhor compreendermos sinteticamente os aspectos da produção desses ambientes virtuais e situá-los junto a discussão espacial posterior que objetivamos realizar, se faz necessário apresentar o que entendemos aqui por Realidade Virtual. 
Meneghette (2010), nos lembra que é milenar o desejo humano de se inserir em outro tipo de realidade, daí a metáfora da imersão ser recorrente, sendo a ideia do batismo, por exemplo, através da imersão na água, um dos inúmeros percursos criados pelo ser humano para simbolicamente criar para si e para um grupo, uma experiência diferenciada em relação à experiência espacial comum. O autor coloca que esse desejo se atualiza, passa pelo desenvolvimento das artes gráficas no ocidente, pelo ilusionismo, pelo cinema entre outras formas de Arte. Nosso contexto de identificação do que seja e de como aconteça a Realidade Virtual, certamente é outro, não se restringe apenas a dimensão religiosa, mas está carregado por elementos subjetivos, identitários.

Muitos de nós que, situados no século XXI, consideramos ingênua a ideia de recriação da realidade apenas a partir de rituais e de uma tomada de consciência derivada destes. É um fato de nosso tempo a indissociabilidade entre aquilo que chamamos Realidade Virtual, a produção e o uso dos sistemas tecnológicos criados para dar suporte às inúmeras formas de RV construídas. Essas experiências diferenciadas em relação àquilo que percebemos cotidianamente e que têm suporte nesses sistemas técnicos, geralmente são todas chamadas genericamente de Realidade Virtual, porém ainda que possamos aceitar essa definição, é importante reconhecer que os diversos artefatos criados por engenheiros e designers são projetos com finalidades próprias nascidas pela colaboração técnico-estéticade diversos agentes em equipes multidisciplinares. Há, portanto, no âmbito do universo de produção tecnológica contemporâneo tipos diversos de RV. Essa diferença é de natureza conceitual e depende do tipo de processo que a tecnologia promove junto ao usuário.

Mais uma vez citando Meneghette (2010), podemos compreender que o que identificamos pela sigla RV pode desenvolver-se através de modos diversos não excludentes entre si. Entre esses modos apontados pelo autor podemos exemplificara simulação (I) na qual há a recriação computacional de um tipo de ambiente real, como o dos simuladores de voo, cujo fim se destina ao treinamento de alguma habilidade humana;a interação (II), que é dada por uma representação eletrônica com a qual pode-se interagir como é o caso da lixeira em um sistema operacional de computador. Representa um modo de RV também a Imersão (III), que já mencionamos anteriormente e nos remete ao uso de softwares e hardwares que isolam o usuário de estímulos visuais e/ou auditivos e os substitui por projeções calculadas com fins na criação de um ambiente. Podemos mencionar ainda a Telepresença (IV) na qual ocorre o acesso remoto realizado mediante o uso de robôs. São exemplos desse último tipo os aparatos usados para desarmar bombas. 
Podemos compreender então que a RV define um ilusionismo digital projetado, onde se pretende que de algum modo o sujeito-usuário estabeleça uma imersão no ambiente virtual. Nesse empreendimento, os engenheiros e designers há décadas têm se dedicado a estudos sobre categorias ligadas a esses ambientes virtuais, amplificando a qualidade de interação humano-máquina.

No âmbito dos projetos de RV é fundamental a consideração de aspectos perceptivos ligados ao espaço - nesse caso espaço entendido como ambiente digital projetado a partir de um conjunto de funcionalidades e fins. Tais percepções espaciais são exploradas em testes cujos resultados são aplicados na melhoria dos projetos desenvolvidos. Há grupos de pesquisadores interessados em desenvolver modelos que colaborem com a ampliação do conhecimento técnico a respeito de como os usuários de ambientes virtuais percebem as medidas espaciais (figura 1). Para tanto, variáveis tais como acessibilidade, visualidade e organização são definidas com a finalidade de compilar modelos de análise dirigidos tanto a plataformas de duas ou três dimensões (USMAN, M.; HAWORTH, B.; BERSETH, G.;KAPADIA, M.; FALOUTSOS,2017). Apenas para ilustrarmos aqui o nível de riqueza de detalhes perceptivos que os projetistas já alcançaram em suas aplicações sobre ambientes virtuais, aspectos como a iluminação e cor em espacialidades virtualmente projetadas foram estudados a ponto de fornecer respostas homogêneas quanto a estados de humor adequados a tipos específicos de iluminação junto a diferentes usuários (MANIA, 2001).

O conhecimento para emular sensações já está bastante apurado em relação a outras variáveis tais como brilho do ambiente, campo de visão, sobretudo, em ambientes virtuais tridimensionais, tais como aqueles utilizados em jogos em primeira pessoa.

Há ainda estudos que objetivam a construção de modelos para avaliar o conforto dos usuários para interfaces de RV. Se considerarmos a RV direcionada para os atuais simuladores de direção, por exemplo, verificaremos que a chamada Experiência do Usuário (do inglês User Experience), se aproxima muito do ambiente fora daquele criado na RV. Isso ocorre, pois nos estudos que levam a cabo o critério conforto do usuário são mensurados, a partir de rigorosos testes, aspectos como a disparidade dos movimentos em diferentes planos e a frequência espacial do contraste luminoso (GENTILIN, J. C.; SHAH, M.; BUCK, A. R.;LINSNER, J.; BOURGET, M. A.; CARROLL, R., 2018).

Todos esses esforços de pesquisa de certa forma nos remetem as questões levantadas por Biocca (1997), em seu artigo produzido no fim do século passado, mas que então já apontava os caminhos e perguntas chave a serem seguidos no campo da RV. A questão central de seu artigo é como a representação do corpo em ambientes virtuais afeta a mente? 
Nesse sentido o autor já indicava a evolução dos estudos voltados a compreender como nossos sentidos percebem os elementos que juntos configuram o ambiente a nossa volta. A ideia básica seria através da pesquisa esmiuçar os itens percebidos e recriá-los em ambientes virtuais, enganando a mente e fazendo o usuário sentir-se presente no ambiente virtual, como se esse fosse o ambiente físico convencional. O percurso anunciado pelo autor de fato se desenvolveu nas últimas décadas, no entanto, sua questão final continua pertinente. No contexto espacial atual, os meios técnicos têm aumentado cada vez mais as extensões de nosso corpo tornando-nos algo como ciborgues, híbridos humano-máquinas, mas precisamos ficar atentos, pois nossa "noção de corpo e identidade podem adaptar-se a esta forma ciborgue" (BIOCCA, 1997, p.20). Para o autor para evitar esse dilema teríamos de rejeitar a tecnologia para evitarmos as incertezas implicadas no dilema.

Figura 1: projetos de modos de exploração em ambientes virtuais

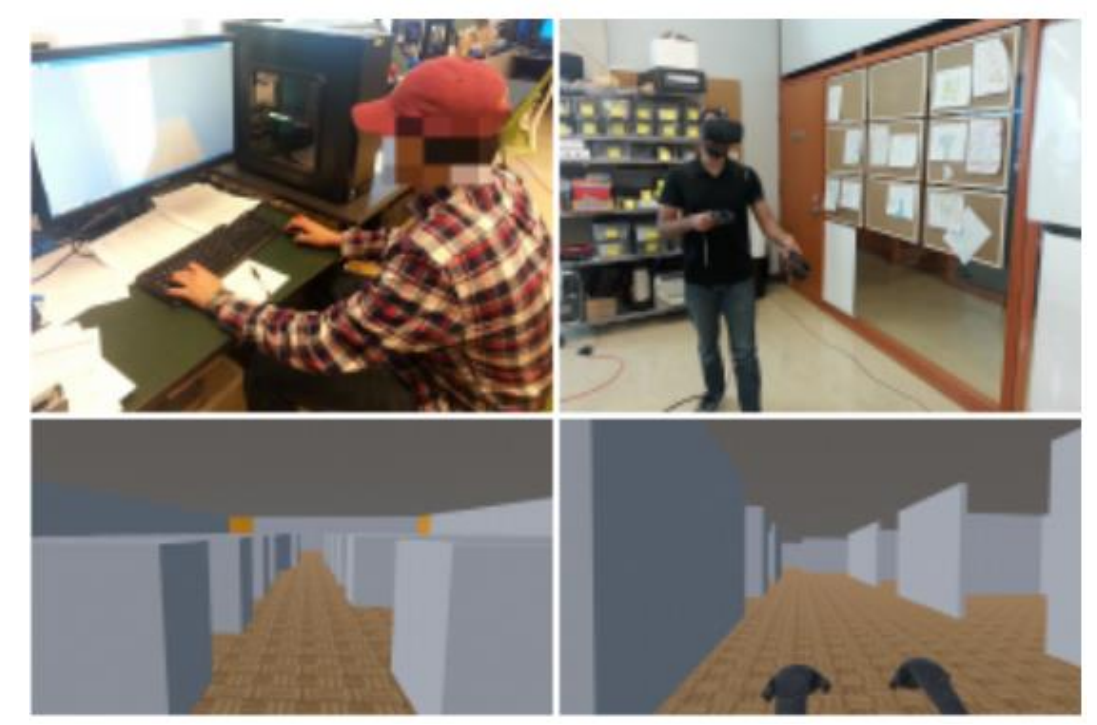

Fonte: USMAN et al, 2017.

As descrições apresentadas se deram no sentido de compreendermos sinteticamente que experiências que envolvem RV. Ações tais como cirurgias realizadas de forma remota com auxílio de braços robóticos ou mesmo a distração corriqueira efetuada mediante jogos eletrônicos, se por um lado nos tornam imersos nos ambientes virtuais, também envolvem processos de produção técnica e criação estética de tais ambientes totalmente artificiais. A $\mathrm{RV}$, portanto, se configura como fenômeno complexo que perpassa as dimensões econômicas, culturais e também existenciais, uma vez que a "criação de sentido corporal na confluência com a tecnologia é um fenômeno de libertação, de liberdade” (MENEGUETTE, 2010, p. 95). Logicamente que essa liberdade é limitada por uma série de fatores, primeiramente pela 
finalidade para qual fora projetado o sistema que desenvolve a Realidade Virtual. Como destacamos os ambientes virtuais são projetados para que os usuários de algum modo se façam presentes neles. Se considerarmos uma abordagem fenomenológica essa presença se dá em uma espacialidade criada a partir dos ambientes virtuais, a qual é passível de ser "habitada" ainda que temporariamente, na medida em que o ser do usuário é absorvido nesse meio enquanto este se expressa e atua, mesmo que de modo condicionado. A ambiência criada a partir das plataformas que emulam RV e que participa de maneira crescente da nossa experiência cotidiana, é o que nos encaminha para a sequência da análise dessas produções de espacialidades virtuais, situando-as no contexto mais amplo do espaço geográfico.

\section{O conhecimento geográfico pensado em sentido amplo, da geografia da localização no espaço geográfico ao valor intrínseco da contemplação da paisagem}

Consideremos uma aula de Geografia em que se solicita a estudantes de cerca de onze anos, que definam sentimentos a partir de espacialidades. A eles fora explicado previamente que lugar é a espacialidade a qual associamos sentimentos, tanto que ninguém diz "odeio ou amo tal espaço", de modo que uma noção geral do conceito de lugar está definida.

Algumas semanas antes, entretanto, tais estudantes haviam tido uma aula de cartografia. Nessa aula eles descobriram que mapas são representações em um plano da superfície da Terra. Fora explicado a eles ainda que essas representações fazem parte do nosso dia-a-dia como nos celulares usados pelos motoristas de aplicativos ou mesmo para representar mundos imaginários como nos mapas de jogos de videogame (figura 2). Como para realizar a tarefa os estudantes poderiam consultar mapas pendurados nas paredes da sala, alguns descreveram que amavam o mundo do personagem Super Mario dos jogos de Super Nintendo, cujo mapa ilustrativo estava exposto entre mapas de diversas espacialidades.

Naturalmente todos riram e atualmente o professor restringe a escolha de pontos da superfície do nosso mundo, a Terra. De qualquer maneira essa história ocorrida há pouco tempo atrás, nos sugere reflexões acerca de como os ambientes virtuais são habitados por nós, se não pela integridade do nosso corpo na maior parte do tempo, ao menos envolvendo nossos sentidos e cada vez mais o nosso imaginário durante boa parte do dia. 


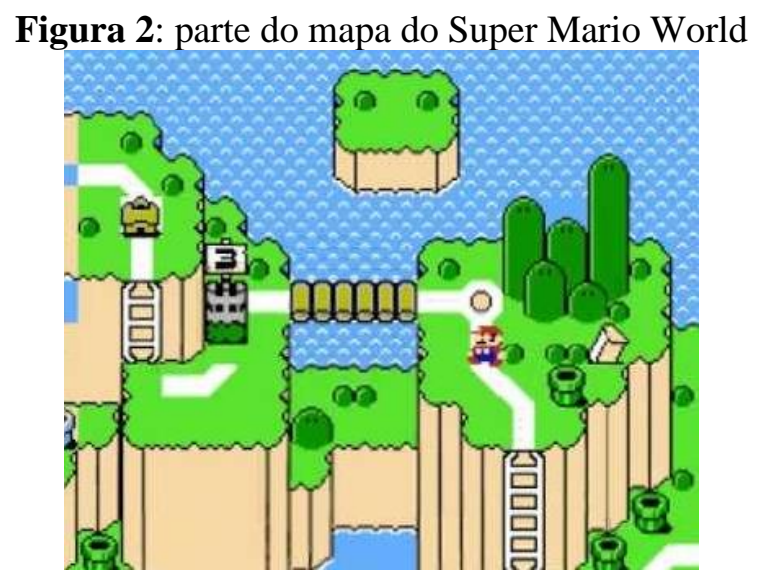

Fonte: YouTube.

$\mathrm{Na}$ seção anterior destacamos o quanto técnicos do terciário avançado tais como designers e engenheiros da computação têm se debruçado em criar conhecimento e aplicações voltadas aos ambientes de RV. Também delineamos que o aprimoramento técnico e estético provém de estudos que possibilitam uma maior imersão do usuário nos ambientes virtuais, ainda que a RV se descreva por uma variedade de modos.

O que as crianças demonstram na sua espontaneidade já haverem assimilado e que os adultos titubeiam em assumir - talvez por muitos manterem em sua memória afetiva o convívio com tecnologias do passado que ainda fazem parte de nosso cotidiano, como é o caso da TV -, é que o volume de aparatos técnicos com os quais interagimos atualmente cresce e com isso se altera nossa percepção espacial e, consequentemente, nosso modo de estar no mundo.Essa situação pode ser sintetizada pela passagem a seguir:

\begin{abstract}
Ao longo da história, os indivíduos sempre se modelaram aos tempos vividos. Hoje, não é diferente: ainda desejamos o bem estar corporal, emocional, profissional e afetivo. Para tanto, a capacidade de adaptação corporal e psicológica aos novos ritmos e experiências se faz presente. Os dispositivos eletrônicos que utilizamos para realizar as tarefas cotidianas estão fazendo papel vital em nossas vidas. Os elementos que antes habitavam as salas de aulas como suporte para o aprendizado eram os livros, réguas, calculadoras, globos, mapas físicos. Hoje, são os celulares, os computadores, os mapas digitais considerados aparelhos móveis de comunicação e informação. Os jovens contemporâneos são dinâmicos e possuem mais facilidade no contato com os meios de comunicação do que com os antigos dispositivos escolares. (CARDOSO e TONINI, 2014, p.19).
\end{abstract}

Vivemos em meios altamente tecnificados, nos quais o emprego de novos aparelhos e a correlata aprendizagem de suas linguagens nos pressiona constantemente, no entanto, nesse turbilhão não costumamos refletir sobre o modo como essas aceleradas transformações técnicas, sociais e perceptivas nos afetam.

Os desdobramentos desse conjunto de transformações - perceptivas, produtivas, culturais, educativas, para mencionar apenas algumas, certamente é incerto se considerarmos 
uma mudança de caráter estrutural em nossas relações sócio-espaciais no século XXI. Não é uma pretensão nossa no escopo de um artigo fornecer respostas a proposições tão complexas. Por outro lado, gostaríamos de apontar caminhos para a reflexão considerando os questionamentos que se desdobram de nossa atuação em um laboratório universitário de RV do sul do Brasil e do ofício docente na área da Geografia.

Pensamos em dois autores que nos possibilitam um pensamento ampliado para compreender melhor os caminhos transformantes do espaço-técnico-informacional em que vivemos. O primeiro é o geógrafo brasileiro Milton Santos, cuja elaboração teórica sobre a condição espacial por nós experimentada hoje está difundida por artigos, palestras, aulas e livros que compõem sua vasta obra, mas que encontra uma espécie de síntese no livro "A natureza do espaço". A teorização do geógrafo brasileiro sobre os conteúdos do espaço do presente pode ser complementada pela abordagem do filósofo francês Gaston Bachelard, cujo pensamento se dirige a análise das frágeis noções de objetividade associadas ao fazer científico dominante.

Ainda que tenha falecido em meados do século XXI, Milton Santos certamente percebeu o papel cada vez maior da tecnologia como um fator da globalização, inclusive na sua materialidade, a exemplo da rede mundial de computadores, a internet. Nesse contexto o geógrafo já havia apontado a negligência da técnica como elemento caro e necessário a uma análise consequente da produção do espaço mundial contemporâneo. Do pensamento de Milton Santos quanto ao tema das técnicas é importante que consideremos as limitações de análises sobre a técnica adjetivada, como na especialidade "técnica industrial".O autor salienta que "só o fenômeno técnico na sua total abrangência permite alcançar a noção de espaço geográfico" (SANTOS, 2006 p. 21). O autor aponta ainda que técnica e meio são inseparáveis, sendo que ambos podem ser identificados como objetos, a exemplo do objeto técnico ou meio-técnico como nos referimos anteriormente. Dentro desse raciocínio o autor qualifica o espaço como sendo,

[...] o espaço é formado de objetos; mas não são os objetos que determinam os objetos. É o espaço que determina os objetos: o espaço visto como um conjunto de objetos organizados segundo uma lógica e utilizados (acionados) segundo uma lógica. Essa lógica da instalação das coisas e da realização das ações se confunde com a lógica da história, à qual o espaço assegura a continuidade (SANTOS, 2006, p.24).

Essa abordagem ampla que o autor nos apresenta para pensar os fenômenos da tecnologia no contexto espacial nos permite vislumbrar que os processos de desenvolvimento das técnicas ligadas a RV, na condição de objetos, se inscrevem no conjunto de objetos 
espaciais, sobre os quais operam sistemas complexos de ações forjadas por uma lógica econômica homogênea.

A RV pode ser refletida a partir de outra escala também, ou por abordagens mais pessoais, o que nos remete fenomenologia. Pensar a RV sob a abordagem da percepção nos direciona a outra epistemologia do espaço, bem como sobre aquilo que concebemos como científico acerca do mesmo. O filósofo francês Gaston Bachelard (1978), desenvolveu uma importante crítica à concepção racionalista de tradição kantiana acerca da noção de categoria entre as quais se destaca o espaço. Para Bachelard a microfísica inaugurada pela teoria da relatividade de Albert Einstein complicou o tripé racionalista formado pela geometria euclidiana, o racionalismo kantiano e a física newtoniana, pois a revolução implementada se desenvolveu a partir de concepções que exigiram imaginação, criatividade matemática e também intuição, o que Bachelard define que acabou engendrando outro paradigma inclusive para a ideia de espaço.

O espaço concebido convencionalmente é objetivamente delineado pela geometria, uma vez que se descreve pela sua mensurabilidade e pela sua visualidade objetiva na superfície terrestre. A realidade espacial sub-atômica por outro lado não se ajusta facilmente a essa espacialidade convencional. Ainda que tal universo espacial seja parcialmente delineável e conhecido por nós, o conhecimento acerca dele foi possível graças a abertura do espírito humano para conformar outra epistemologia, outras dimensões espaciais.

Bem, a RV é filha das aplicações da micro-física, assim como a maioria esmagadora das técnicas que configuram nossas espacialidades hoje. Muitas abordagens da geografia contemporânea consideram a influência do pensamento fenomenológico induzido por Bachelard e outros pensadores do século XX. As espacialidades reconhecidas pela percepção descrevem uma noção atravessada pela subjetividade dos sujeitos que se situam sobre um espaço objetivo, mas o compreendem de inúmeras formas, cada qual filtrada pelas memórias e identidades dos indivíduos. Nessa perspectiva, não é sem sentido afirmar que as formas criadas de RV, produzidas a partir dos aparatos disponíveis que se multiplicam, conformam impulsionadores de espacialidades subjetivadas pelos sujeitos e condicionadas pelas infraestruturas eletrônico-digitais. A particularidade dessas espacialidades é que elas se forjam como representações da representação virtual construída, definindo uma condição espacial marcada pela forte artificialidade.

Finalmente, para que possamos compreender a produção espacial do mundo globalizado pela técnica em sua complexidade é fundamental usar de uma abordagem 
dialética no âmbito de um pensamento científico aberto que agregue tanto o subjetivo como o objetivo, pois

[...] basta, aliás, verificar psicologicamente o estado de inacabamento da ciência contemporânea para ter uma impressão profunda do que seja o racionalismo aberto. É um estado de objetiva surpresa diante das sugestões do pensamento teórico. (BACHELARD, 1978, p. 177)

Nossa impressão é a de que experimentamos uma explosão perceptiva de espacialidades fabricadas virtualmente, a partir, sobretudo, da parafernália desenvolvida pela RV. Não seria possível, nem é nossa intenção fazer um juízo de valores sobre a qualidade dessas experiências, sobretudo porque, como apontamos na seção anterior, não há uma RV, há de fato diversos modos e projetos de RVs. De qualquer forma é necessário pensar dialeticamente o espaço que agrega os sistemas de objetos e ações produzidos, e que em seu conjunto se forja como uma matriz onde se conjugam as dinâmicas naturais e das sociedades sob a homogeneidade de uma lógica econômica. Nesse contexto, apontamos como problemático o fato da percepção humana sobre as espacialidades naturais, isto é, aquelas não criadas pelo gênio humano, tornarem-se cada vez mais residuais junto ao imaginário coletivo. Prova disso é o fato do racionalismo científico dominante em muito colaborar com o desenvolvimento de infraestruturas insustentáveis ambientalmente. Além disso, muitas das técnicas digitais que criam a RV, também fomentam sistemas de câmeras, o funcionamento de edificações inteligentes efetivando a seletividade do espaço público urbano, sustentando experiências injustas e desiguais, sobretudo nas cidades.

Nesse contexto é fundamental que soluções para as ameaças ambientais que nos assolam atualmente - como é o caso do aquecimento global e das pandemias -, se definam a partir de uma tomada de consciência de grandes contingentes humanos, o que certamente perpassa uma cosmo visão mais rica, existencial e ecologicamente. Falamos daquilo que Bachelard chamou de um novo espírito científico, capaz de criticar-se e reinventar-se diante dos desdobramentos indesejáveis das experiências efetuadas. A promoção dessa cosmo visão se faz necessariamente através de uma nova pedagogia, pois precisamos "compreender que a aquisição de uma forma de conhecimento se traduz automaticamente numa reforma do espírito. É, pois, necessário dirigir novas investigações no sentido de uma nova pedagogia" (BACHELARD, 1978, p. 77). Acreditamos, portanto, que o fazer técnico, condicionado principalmente por fatores ligado a homogeneidade da ordem econômica, por ele mesmo reflete cosmo visões cujos compromissos pouco favorecem causas sociais e ambientais justas que dirigem-se contra os problemas estruturais que afligem a todos. 


\section{O breve relato sobre uma experiência que envolveu Ensino de Geografia e a RV}

Como mencionamos inicialmente esse artigo possui um caráter mais especulativo quanto as noções mais generalizadas de espaço principalmente quando este último é mediado pela tecnologia. De qualquer forma apresentaremos algumas ideias a partir de uma saída de campo de geografia realizada em 2019 com estudantes do ensino fundamental de uma escola municipal de São Leopoldo (RS). Na ocasião, tais estudantes visitaram o Vizlab/X-Reality and Geoinformatics Lab, que é um laboratório multidisciplinar focado em GeoInformática e Visualização 3D, situado dentro da Universidade do Vale dos Sinos (UNISINOS - campus São Leopoldo). Este laboratório está vinculado aos programas de Pós-graduação em Computação Aplicada (PPGCA) e Biologia (PPGBio), o mesmo proporciona formação em níveis de mestrado e doutorado, principalmente ligada a indústria de óleo e gás.O propósito da visita em questão ligava-se a um projeto experimental que envolvia uma sala virtual de aprendizagem na qual os estudantes poderiam conhecer alguns animais da fauna de diversas partes do mundo.

Dentro do escopo da discussão que aqui desenvolvemos podemos analisar que dessa atividade educativa uma série de elementos destacados nesse artigo se refletiram perceptivelmente nesse grupo de quase trinta estudantes. A própria saída de campo para fora dos domínios da escola já configurou um fator de encantamento para as crianças que possuem uma mobilidade por vezes limitada ao trajeto escola/casa. Como havíamos destacado, o espaço público da cidade é muito percebido atualmente como aglutinador de espacialidades nas quais predomina a insegurança, portanto uma crescente mediação técnica é compreendida como necessária para minimizar tal condição. Desse modo, estas crianças na sua maioria diferem daquelas do tempo dos seus avós que brincavam na rua, tomavam banho em sangas, tal como alguns relatam. Apesar de breve a visita, dispúnhamos de pouco tempo de modo que nem todos os estudantes usaram as ferramentas de RV disponibilizadas pelos gestores do Vizlab, os estudantes se mostraram bastante familiarizados com tais instrumentos (imagem 3).

No caminho de volta a escola o clima lúdico entre o grupo era generalizado. Ao ser perguntado se havia gostado da atividade de ensino com RV um estudante respondeu com ar irônico "a realidade da sala (virtual) é a verdadeira realidade, isso aqui (o lugar comum da cidade onde nos encontrávamos) é que é uma ilusão". A resposta surpreendente seguida de riso engendra certamente múltiplas interpretações. Dela, no entanto, não é possível deduzir se representa um entendimento isolado vindo de uma pessoa cuja personalidade se forma imersa em meios técnicos ou se define um contingente que marca toda a sua geração de crianças. 
Imagem 3: ferramenta de RV do Vizlab/Unisinos

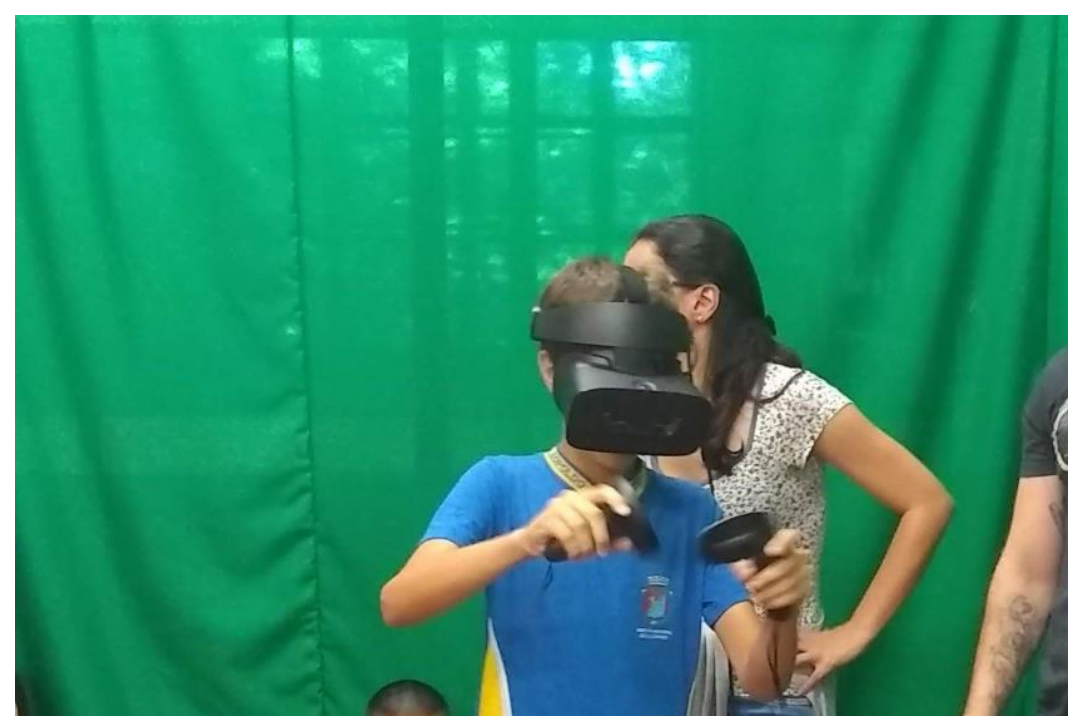

Foto: Branda Weppo/Vizlab.

Representa certamente um dado evidente o fato do condicionamento tecnológico massivo na atualidade influenciar a juventude em seu conjunto ainda que em níveis diversos. Também é notório que tal influência não tem sido acompanhada da promoção, através desses meios técnicos que são muitos, de um proporcional autoconhecimento e da consciência de nossa interdependência físico-biológica com o ambiente natural.

\section{Considerações finais}

Buscamos com o presente texto estabelecer algumas reflexões sobre o contexto de desenvolvimento tecnológico que tem redefinido muitas de nossas relações espaciais, bem como, nosso entendimento sobre o próprio espaço. Nesse âmbito encontram-se os diversos aparatos que promovem modos e projetos variados de Realidade Virtual (RV). Consideramos que as técnicas definem um fator nos processos de produção espacial contemporânea que envolvem os sistemas de técnicas/objeto e ações. As tecnologias que tornam possível a RV descreverem múltiplas experiências e projetos, no entanto, o espaço globalizado que a permeia direciona o conjunto de eventos no sentido de estabelecer uma racionalidade econômica. Nesse âmbito ponderamos que se encontra na própria essência dessa racionalidade dominante, uma concepção de ciência que nos possibilita compreender o espaço em que nos situamos por uma abordagem essencialmente instrumental de suas propriedades mensuráveis. Noções ampliadas, diferentes de espaço e também de ciência, entretanto, nos possibilitaram o avanço técnico que temos hoje, incluídos nesse o avanço os aparatos que proporcionam RV. 
Apesar de toda essa tecnologia e de todas as suas inovações, em nossas experiências espaciais inclusive, o entendimento científico generalizado entre nós encontra-se ainda muito permeado por velhos parâmetros de ciência, isto é, o de ciência como instrumento, como meio meramente desenvolvedor de técnicas. Ainda que essa seja uma dimensão do fazer científico, compreendemos que o arcabouço de conhecimento disponibilizado até hoje é fruto da aventura do espírito humano sob um olhar aberto junto aos domínios naturais da Terra e do próprio universo, sendo essa uma verdade espacial e científica pouco reconhecida. Nesse contexto, seria relevante, em que pesem os grandes desafios ambientais do presente, que o desenvolvimento técnico voltado para a promoção de realidades virtuais pudesse colaborar com a difusão de uma pedagogia científica e espacial aberta. Os modos de RV podem colaborar, portanto, com novas cosmo visões que possibilitem aos sujeitos reconhecerem-se como agentes imersos em um rico conjunto de espacialidades definidas por reconhecíveis dinâmicas artificiais e naturais, as quais nos demandam cada vez mais ações sustentáveis nesse século XXI.

\section{Referências}

BACHELARD, Gaston. Coleção os pensadores. São Paulo: Editora Abril, 1978.

BIOCCA, Frank. The cyborg's dilemma: progressive embodiment on virtual environments.Jornal of Computer mediated-communication (online) [3], 2. 1997. Disponível em: 〈http://ww38.ascusc.org/jcmc/vol3/issue2/biocca2.html〉. Acesso em: mai. 2020.

CARDOSO, Juliana Carvalho. TONINI, Ivaine Maria. Os meios de comunicação, tecnologias digitais e práticas escolares de geografia. EM: 2014, Florianópolis. Anais eletrônicos do ENPGSUL.Florianópolis: UFSC, 2014. Disponível em: <http://anaisenpegsul.paginas.ufsc.br/>Acesso em: mai. 2020.

GENTILIN, J. C.; SHAH, M.; BUCK, A. R.; LINSNER, J.; BOURGET, M. A.; CARROLL, $\mathrm{R}$. Computer analysis of user comfort in virtual reality environments. [S.l.]: Google Patents, 2018. US Patent App. 15/214,427.

MANIA, K. Connections between lighting impressions and presence in real and virtual environments: an experimental study. In: Proceedings of the $1^{\text {st }}$ international conference on Computer graphics, virtual reality and visualisation. [S.1.: s.n.], 2001. p. 119-123.

MENEGHETTE, Lucas Correia. Realidade virtual e experiência do espaço: imersão, tecnologia e fenomenologia. São Paulo: PUC-SP Dissertação de mestrado em Tecnologias da inteligência e design digital. 2010.

SANTOS, Milton. A Natureza do Espaço: Técnica e Tempo, Razão e Emoção. São Paulo: Editorada Universidade de São Paulo, 2006. 
USMAN, M.; HAWORTH, B.; BERSETH, G.;KAPADIA, M.; FALOUTSOS, P. Perceptual evaluation of space in virtual environments. In: Proceedings of the Tenth International Conference on Motion in Games. [S.1.: s.n.], 2017. p. 1-10. 